\title{
PICTURING THE WINTER OLYMPICS: THE OPENING CEREMONIES OF NAGANO (JAPAN) 1998 AND SALT LAKE CITY (USA) 2002
}

\author{
ALAN TOMLINSON \\ University of Brighton, Eastbourne, UK
}

\begin{abstract}
This article examines the symbolic content of large-scale sporting events as expressed in the opening ceremonies of the Winter Olympic Games of 1998 (Nagano, Japan) and 2002 (Salt Lake City, USA). Such internationally broadcast events are claimed widely to contribute to the transformation of a city's or a region's image, and to potential concomitant—and predominantly economic — benefits. Drawing upon the live coverage of these events by the British Broadcasting Corporation (BBC), the article shows how the opening ceremonies balance the local, regional, national, and international emphases in the presentation of the Olympics and the host city/nation. Nagano 1998 proritized the themes of peace and harmony, mixing ancient Japanese cultural elements with elements of an international populism. Salt Lake City 2002 was the first Olympic Games to be held after the attacks on US targets of September 11, 2001. The security was unprecedentedly tight, and the ceremony showed how the claimed universalism of the Olympics can be appropriated into a particular nationalist cause and merged with a set of national values (including the rhetoric of hard work, ambition, and the chasing of a dream). The Nagano and Salt Lake City cases confirm the process whereby the Olympic spectacle and its accompanying values are commonly and recurrently reworked in the interests of the host nation. The article concludes by locating the ceremonies as forms of consumer tourism, but questions the long-term impact of such events in worldwide terms, when they are framed for and are most meaningful to their more immediate and local constituencies.
\end{abstract}

Key words: Winter Olympics; International broadcast; Opening ceremonies; Destination image; Symbolic content

\section{Introduction}

There are several reasons-or perceived benefits-that account for why cities compete to stage international sporting events. These reasons, particularly in the context of the Olympic Games, go beyond any explicit claim that the city and the nation are committed to the ideals of a particular sporting philosophy. Hosting such events acts as a galvanizing force for the updating or even transformation of the urban infrastructure, particularly in transport and communications; claims are made that the event will boost the local economy, creating a range of jobs and employment opportunities; projections are made 
of unprecedented levels of tourism visits after the event; and worldwide media coverage buys publicity and image enhancement on an unlimited level. Less tangible than any of these is the symbolic impact of a successful event.

The symbolic impact can be dramatic and long lasting, outstripping the other reasons in the retrospective justification for all that is committed to an event. It has been claimed that the most researched Olympic Games was the Summer Games in Barcelona in 1992 (Kennett \& de Moragas, in press), though the 1936 Nazi Olympics in Berlin has generated volumes of scholarly output, and Sydney 2000 is generating a vast amount of research data on all aspects of the planning for and the staging of the event. But it is certainly true that Barcelona generated systematic analysis of the sporting, social, and economic legacies of the Games. It became a model of success from which succeeding host cities could learn. This would never be a simple task of emulation. The organizers of Atlanta's centennial modern Olympics in 1996 knew this, and left Barcelona extremely concerned at how the US's deep south city could possibly match the dazzle, sparkle, and overall spectacular impact of Barcelona. Barcelona's Mediterranean setting and Catalan culture, the mountainous backdrop of the city, its pedigree of classical history, all these were elements that Atlanta simply did not have. Sydney could match the topographical spectacle of Barcelona, with its waterfronts, the iconic Opera House, and its dramatic harbor bridge. The worldwide audience remembers these features, and city profiles can be dramatically raised in the global consciousness. But the Games also move on. Soon it is another city's turn. Economic forecasts and tourist or visitor projections begin to gather dust on the shelves or in the archives of the city authorities and the erstwhile organizing committee. The city may be best remembered for how it presented itself, and especially for how it presented itself in the ceremonial side of the event. But a global audience's memories of 2 weeks of television will not translate automatically into block bookings and the influx of millions of tourists.

The figures cited for tourist-fostered economic benefits can vary wildly. As the British government prepared to support a London bid for the 2012 summer Olympics, the prospect of $£ 350-680$ million of indirect, nonfinancial benefits was highlighted in its consultant's report (Arup, 2002, p. 8). Even more mouth-wateringly, Atlanta was reported to have assessed $£ 3.2$ billion of tourism benefits; Sydney, cited from the IOC official report, as if this were a stamp of legitimacy, assessed $£ 4.2$ billion of such benefits, "of which $£ 2.4$ billion was additional tourism" (Arup, 2002, p. 8). Reading such figures, rarely presented in any audited detail or retrospectively evaluated light, it seems that the Olympics is an unmissable opportunity to expand tourist markets. But the relationship between the early, optimistic claim and the actual ante-event benefits is too often neglected. As an albeit modest and small-scale intervention, in this article I look at the ways in which the cities of Nagano in Japan and Salt Lake City in the US presented themselves and the events that they were hosting in the Winter Olympics, and consider the potential impact of their modes of presentation upon an hypothetical tourist consciousness.

\section{Claims, and Hopes, and Flames}

In his closing ceremony speech at the 1992 Games, International Olympic Committee (IOC) president, Juan Antonio Samaranch, speaking in his home city where he had served Fascist dictator Franco with such distinction (Simson \& Jennings, 1992), gushed with pleasure:

Thank you Barcelona. Thank you Catalonia. Thank you Spain

These have been without a doubt the best Games in Olympic history ... Barcelona will not be the same in the future. Nor will our sports be the same after the great victories achieved. (cited in de Moragas and Botella, 1995, p. 7)

Such an endorsement, acting as a kind of worldwide advertisement, has stimulated a continuing competition for the status of host city of either the Summer or Winter Games. The core of this article comprises my critical readings of the BBC's live coverage of the Winter Olympics of 1998 and 2002. I have previously covered both Winter and Summer Olympics in this way, in a range of publications, and in this article show how both Nagano and Salt Lake City conform to the recurrent pattern in the symbolism and ideology of Olympic ceremony. The general question of the relation between such forms 
of image construction and self-presentation, and the more tangible if not strictly measurable benefits of hosting such events, is then discussed in the light of the two cases.

\section{Nagano 1998: Peace and Harmony}

The BBC began its coverage in typically clichéd fashion, anchorwoman Sue Barker reminding viewers that the Opening Ceremony was just moments away, that the Games would be the stuff of dreams, and that the Games would draw us into the dramas of the circumstances that would dictate precisely "whose dreams would come true"; and that the people of the Olympic city of Nagano have been waiting to make the world welcome. All Olympic hosts have an eye on their predecessors, and Barker reminded us of this, with the observation that Lillehammer, in Norway in 1994, put on a "magic and memorable" opening, and would be "a hard act to follow."

The broadcaster at the event was experienced premier sports commentator Barry Davies. His opening materials did not look too promising: shots of a fairly bleak and colorless stadium surrounded by distant but gray and somber-looking mountains. In daylight too, so the grayness could not be cancelled out by nighttime illuminations. The first piece of action was the ringing of a bell that was cast in 1667 , at a local shrine that has been visited by 7 million people. This was rung by a man who, at the end of World War II, when little more than a boy, was being trained as a kamikaze pilot when the war ended. On this note of hope, survival and peace was rung, in Davies's words, "the first note of the final Olympics of the century." Attention then swung to the Minami Stadium, full to capacity with 50,000 wellwrapped spectators. Nagano is a city of 360,000 , its temple said to be the site of the original Buddhist shrine. The legacy of a particular form of religiosity was being foregrounded in this opening to the opening. Davies picked up on this tone and theme, anticipating a ceremony that would be "simple, dignified and spiritual."

Not being a throbbing cosmopolitan center, or a world-renowned landmark, Nagano and the Games' organizers knew that they would need some help in hitting the right global notes. Right at the beginning, then, viewers were whirled around the world, in ech- oes of the global broadcast on the Millennium Eve, a little over 2 years before. People were filmed at the Brandenberg Gate, that central checkpoint between East Berlin and West Berlin during the Cold War years before the collapse of East European communist states including the German Democratic Republic. Five rings of colorfully clad vocalists were clustered together in Sydney, at the side of the Opera House. The Tanglewood Festival Chorus was ready for action in the General Assembly Hall of the United Nations, in New York. More Olympic extras and participants were to be found at the Forbidden City's Gate of Shen-Wu, Beijing. And it looked like party time at Fate Bay, Cape Point, Cape Town. These contributors brought into play representatives from all five continents symbolized in the five rings of the Olympic logo. It was an effective move by Nagano to make a worldwide impact right from the start. But it also deflected from a sense of where the Games were actually taking place. All the other places sounded grander, looked more interesting, than this unknown Japanese provincial township.

The ceremony proper began with a local ritualistic tradidtion. Giant logs were brought down from the heights in the region, to purify the earth. Their Japanese name meant "sacred pillar." Men sat astride these trees, or at least sought to cling to them precariously, and wave yellow streamers, as other men and women from the community sustained a consistent chant- "the more plaintive part of the log chant" being a "prelude to much hard work," as Davies said, having made links here to comparable ceremonies in Tibet, Thailand, Mexico. Maypoles, too, in England, might be the same sort of thing, he added, sounding far from confident in his cross-cultural expertise on such folkloric detail. The trees, 12 meters high and weighing 2 metric tons, were raised from their horizontal position. The yellow streamers were used to call the gods that had lived in the trees-to do what, we were not told. Davies spotted the nature connection though, pointing out that there is "great concern at these Games for the environment." By now-as a television viewer I'd found this pretty tortuous viewing so far-we might wonder how people in the stadium were enjoying themselves. As the camera scanned the stadium seating, Davies noted lots of "smiling faces ... we'll see plenty of these" among such "a warm people, a 
hugely polite people." Davies reciprocated this kindness with the generous comment that this tree ritual had given the ceremony an "expected colorful start. ... And now, as the chanters depart," the air of expectancy was heightened still further. A percussion background then heralded a switch from the local culture to the national cultural icons of Japan's top Sumo wrestlers. Their ring-entry ceremonies also echoed a long historical pedigree, traceable back to an 8th century text. Davies, well briefed on this by his media pack, informed us that Sumo became the national sport in 1909, and that the Hawaiian-born Grand Champion, 6 feet 8 inches in height and 30 stone in weight, was "an enormous man, hugely popular in this country." As if realizing the triteness of his observation, Davies added something more interpretive, seeing in the Hawaiian "a wonderful mixture of pride and deserved arrogance," and joking that we would not really want to pick a fight with this man. Meanwhile, the Emperor had arrived with his wife and the president of the IOC, Juan Antonio Samaranch, whose last ice-show as top man this would be. The ceremony so far was one-paced and dull, rather like the Grand Champion himself, at least in the eyes of the non-cognoscenti. It is hardly credible that millions worldwide would be sitting up through the night watching this diet of village festival, school concert, and West End or Broadway dance on ice.

Reaffirming the iconic status of the Grand Champion, Davies the linkman then led us from the "god of today" (or perhaps he was alluding to the Japanese Emperor or the IOC president) to a "god of the past . . . ancient gods." Children of Nagano invaded the ice, dressed in mino coats of straw, reed, and Japanese linden, traditional outfits of Japanese fishermen who had to combat the cold. The ancient gods-they looked like haystacks bound by knotted ropes, on wheels-were there to ward off the evil spirits, and so protect the children. Effectively protected, the children suddenly stripped off their fisherman's coats, and turned into snow children, wearing costumes in the colors of the flags of the participating nations. Ryoko Moriyami led them in a rendition of Andrew Lloyd Webber's When Children Ruled the World. It was a short reign as the children soon sped from the stadium, we were informed of the IOC's contemporary feel in adding snowboarding, curling, and women's ice-hockey to the Olympic schedule, and the interminable parade of the athletes began. On Norway's appearance, it wasn't their record haul of Winter Olympic medals over the years that got Davies going, but a veiled evaluation of the show so far in comparison to the 1994 Lillehammer host: "a huge standard for the Japanese to follow," Davies almost whispered, tailing off with the implication that we could make up our own minds whether or not the Nagano event was matching that standard.

The set ritual continued with the IOC president anticipating the Games as "a great success," the arrival of the Olympic flag, and the playing of the Olympic anthem and then the Japanese national anthem. The torch relay then became the focus, with one-legged, one-handed Chris Moon from the Landmine Survivor Network approaching the stadium with the Olympic torch, 1 of over 7000 people to have been involved in the relay. Hiromi Suzuki, world champion marathon runner in Athens the previous year, was the penultimate runner, handing the torch on to Midori Ito, silver medalist in ice-skating in the Albertville Games, and known as the Japanese jumping bean. She looked very different here, gowned up in elegant, full-flowing classical costume. She was raised to the cauldron on a platform to light the Olympic flame. The cauldron was atop a spiky, angled construction, "a welcome variation on tradition," said Davies, adding that this was very different to the French fries container at the Atlanta Summer Games 2 years before. Olympic oaths then preceded the concluding act, which relied on a cast of 8 soloists, 5 choirs, and 81 ballet dancers, and linking back up with the performers in Sydney, Berlin, Beijing, New York, and Cape Point. Davies called this climax "heartwarming." Back in the BBC studio in London Sue Barker commented that the show may have lacked a degree of "razzmattaz," but "it had peace and harmony."

\section{Salt Lake City 2002: "A Great Show or What?"}

Barry Davies of the BBC was on duty again in February 2002, in Salt Lake City, Utah, in the US. Security was tighter than at any cultural event in history, just 5 months after the September 11, 2001 attacks on the World Trade Center in New York and the Pentagon in Washington, DC. People had waited for 2 or 3 hours to get into the stadium. "The chill of 
the night" meets the warmth of the occasion, observed Davies. The chill of the night could also be heard in the inadvertent soundtrack to the broadcast, the sinister whirr of the helicopters hovering over the stadium. If Nagano was the Sacred Games, these were the Security Games.

It was a colorful setting, pitch black skies and a dazzling bright blue centerpiece, a laser show shooting upwards as if to elevate the stadium and the event into the heavens, an Ascension Day (or Eve) in which to symbolically reclaim the skies. The audience would not be sitting by passively. They all wore white capes, and were armed with torches, extras in a show of self-confidence and defiance that would have more to do with the restoration of US pride than with universal Olympic spirit. Salt Lake City broke with Olympic precedent in a memorial event for the September 11th event and its victims. Dr. Jacques Rogge, IOC president, Mitt Romney, president and chief executive officer of the organizing committee, and George W. Bush, US president, walked in, solemn-faced, bedecked in mourning black. The US flag that flew at the World Trade Center on September 11th was then carried into the stadium by 14 athletes, in outfits of paramilitary design and navy blue hue. Romney was reported as saying that "concern about precedent is surely outweighed by concern about such an unimaginable tragedy." Seventyseven countries would be competing in the Games. People from 80 nations lost their lives in the New York attack, and these Games, it was reasoned, were the first time that the world had gathered together since that date. The opportunity should be taken, then, for "a very public grieving." The US national anthem was sung, led by the Utah Symphony Orchestra and the Mormon Tabernacle Choir. Rogge stood motionless, arms rigid in respect. Romney and Bush crossed their hearts with their right palms. The battered remnant of a flag was raised, to the anthem "the land of the free and the home of the brave." The Salt Lake City Olympics was starting with the most explicitly political display since the Berlin Nazi Olympics of 1936.

The cultural show preceding the set ritual of an Olympic opening ceremony centered upon a Child of Light, an angelic-looking early adolescent boy dressed in red, innocent in head-warming woolly hat, holding a lantern before him, looking to find the right way, to lighten our way out of the darkness. The setting in which he finds himself is that of a magical forest. The theme for the performance is that of the fire within all of us that cannot be extinguished. A haunting female voice reminded us of this: "None of life's storms can darken the human spirit once it is alighted within." The Child of Light-let us call him Redcap—skates between tall, stilted specimens, in a brewing storm (we know this because there are huge swathes of white fabric being waved in the air, and because Davies summarizes the media "cribsheet" for us). Redcap is turned away by hostile ice warriors, slimy looking crouched figures, serpent-like, dressed in flashy silver-gold, scalylooking and threatening. But Redcap has the fire within. And a savior arrives. A young flaxen-haired Adonis, also dressed in red, appears. It is the $\mathrm{Hu}-$ man Spirit, leading the boy through the storm of life. Redcap is doing well, skating precariously and eventually safely through this storm, evading the flapping attentions of layers of what now look like billowing parachutes. Barry Davies enters the spirit: "The Fire Within and the Child become as one to cut a blazing path of high energy through the storm." Hundreds of children flood the ice, to join Redcap and to confirm that the storm is tamed. Redcap will be back, and indeed, this Child of Light would appear at every medal ceremony throughout the Games. But, the storm tamed, it was time for the parade of the athletes. It is traditional for Greece-home of the ancient Olympics, and host of the first modern Olympic Summer Games - to lead the parade, and for the host nation to enter the arena last, the rest in alphabetical order. Seventy-six countries could be cheered before the arrival of the US team, whether the national team comprised 157 competitors (Canada), or was a one-man team (Thailand), whether it was a contiguous neighbor (Mexico) or a distant, different culture (Islamic Republic of Iran, for whom there was a "welcome again warm," Davies noted). The commentary stuck to playschool geography here rather than grown-up global politics, reminding us that Monaco was the second smallest country in the world, or that Andorra was in the Pyrenees, or that Nepal was "the home of Everest." More interestingly, as Davies said, there was "huge enthusiasm for every team ... what it will be like when the Americans arrive, heaven knows."

Well, it was noisy, colorful, patriotic, celebratory, self-congratulatory. The camera zoomed in on Bush 
and Rogge. The Olympics was off the agenda for the moment. This was a reaffirmation of the American spirit and national pride, not a general expression of some universal human spirit. It was an acclamation of post 9/11 America. Children rejoined the action at the end of the parade, the camera switched to an aerial view of what was now a defiantly bright flame-colored arena, a fire within ignited despite any outside threat. A trumpet fanfare welcomed all the athletes, and laser shots and fireworks provided a climax to the parade- "a spectacular display, albeit brief," said Davies, though there was a lot more to come. The stadium fell into almost darkness, and the cultural show began.

The five original nations of the state of Utah took center stage, each from a different area of Utah. These included the Shute, the Shoshone, and the Navaho, played in, along with the other two peoples of Native Americans, by pipe-playing peers. The theme here was of coming together, as the leaders of the five nations offered individual but complementary greetings of welcome to selected individual athletes. Pounding drumming rhythms followed, from percussion groups outfitted in Olympic colors, providing the soundtrack for ceremonial dances of the five nations (peace dances, presumably, though the libretto was at best minimalist at this point). Davies came alive in the commentary position, noting a presentational process that was "slowly mixing the traditional with the contemporary," as singer Robbie Robertson took the stage. Son of a Jewish father and a Mohawk mother, Robertson's rich cultural pedigree allowed Davies to say how the show was demonstrating how all hearts could beat as one. Robertson's songs kept the main theme of the ceremony going strongly. He addressed a greeting to the athletes of the world, the peoples of the world, and expressed respects to the five nations of Utah. His songs combined defiance and liberty: "making a noise in this world ... won't go quietly ... that's how we know who we are"; and "go on and stand there on the mountain ... setting your spirit free." As Robertson, accompanied by Rita Coolidge among others, sang these lyrics of liberty, the camera focused on the US flag, and we were informed that the Olympic torch relay had now arrived in Temple Square in downtown Salt Lake City. Spanish missionaries, English, Chinese, Irish, and others were then catalogued as historical influences on the cul- tural formation and mix of the region. Mormon pioneers, coming in 1847, preceded by European explorers, and fur traders in northern Utah, received honorable but cursory mentions-extraordinary in the case of the Mormon sect whose separatist philosophy and religious fundamentalism became the ideological basis of the city's establishment and growth. But the ceremony passed swiftly over this and took on an environmental emphasis. A balladsinging cowboy in the outdoors, a Mark Twain voiceover on the West as a fairyland and place of enchantment and awesome mystery, and the image of the lake turned into a glistening waterhole around which a moose, a giant roaring bear, flying fish, and flying rabbits gathered and swarmed. Bluegrass music accompanied skiing coyotes. By now Barry Davies seemed lost for words. A herd of white horses passed by, a snow-white bison was to make its appearance, and Davies made his comeback, as if awoken by "the rattling sound of a 70 foot coiled snake." This pantomimic menagerie, a papier-mâché prehistory of the human colonization of the American land, exited as Davies observed that "one by one the stars of the night disappear," and "the fire within burns brightly," heralding "the sunrise of a new day."

The deep bass tone of the male Voiceover then commented on "the moving sun rising over the East ... with spirits uplifted, a rendezvous was called and so began, neighbor to neighbor, in the music of togetherness." All animals and Native Americans recognized and dealt with, the stage was now taken over by jigging and reel-dancing pioneering Americans, the iron horse of the railway looking a mite frail in its paper form, as it steamed down an aisle of the stadium. In 1869 the railroad had arrived just north of Salt Lake City, and this symbol of modernity was the backdrop to the performance of the Dixie Chicks, singing "I'm gonna be ready this time ... ready to run ... ready to do and have some fun." A little boy in dungarees was skipping around the stadium to this invitation. By now the flame was on 13th Avenue, 11,500 people had carried it, and the latest John Williams composition was about to be delivered by the Utah Symphony Orchestra and the Mormon Tabernacle Choir. Williams himself was conducting the performance, on his 70th birthday-another all-American great not to be bypassed in this most US-American of ceremonies. 
On the chorus of the Williams number, a tribute to the Olympic mantra of faster, higher, stronger, poles of laser light veered towards a central podium in the arena, and Rogge and Romney reentered the arena. "Is this a great show or what? And how about that volunteer cast, huh?," Romney asked grinningly and boomingly, to be greeted by huge cheers of affirmation. His speech was to be a speech to stretch the emotions. Here are some snippets:

Children around the world are dreaming ... dreaming of daring performances, cheering friends and proud parents ... our aspirations, and those of our children and grandchildren can become reality.

We salute you Olympians, both because you dreamed and because you paid the price to make your dreams real...you guys pushed yourselves, drove yourselves ... sacrificed. All Olympians stand on the shoulders of others, those who lifted them.... Let's also cheer the parents, coaches and communities ... alright!

It does not take any complex theoretical framework to pinpoint the key meanings of such a speech: dream, ambition, hard work, longevity, interdependence. These are the themes of the Olympic baggage of ideas, given a particular gloss and presentational style. Romney then lowered his tone, switched from smile to solemn look, and gave the Olympic theme of peace a special twist:

After September more than ever before our generation longs for a world where the dreams of all the children may come true, where aspirations can be nourished in homes with caring families and in nations which embrace peace and the rights of humankind ... in such a world the greatness of achievement will be measured by the greatness of dreams and by the fire and passion in the hearts of the dreamers. Olympians, the world watches you not just to be inspired by spectacular athletic performance, but to be inspired by the spirit and fire that inspires you. You skate and ski and our hearts quicken with your dreams. We find ourselves happy for you, praying for you. I see the Olympic Games as a symbol of the fire that drives you to fulfill your dreams. May the fire we see within you light a fire within each of us.

Mitt Romney had inherited the role, as those implicated in the bribing scandals that had secured the Games for the city (Jennings \& Sambrook, 2000) had been levered out of position. Jacques Rogge was new to his role too, presiding at his first Olympic
Games, successor to the controversial dictatorial Samaranch, who had held the IOC presidency for 20 years. Rogge wasn't renting palatial properties, or staying in luxury suites in top hotels. He was residing in the athletes' village. It was a difficult debut for him. How would he manage the Olympic image in this emotion-filled post-September 11 moment?

I greet our wonderful American hosts. I greet the youth of the world. ... Your dream has come true. Years of dedication and hard work have been rewarded. . . A A champion is more than a winner, someone who accepts the rules, rejects doping, and competes in the spirit of fair play. All of you can be champions regardless of your final ranking. ... [pause and thunderous cheers] People of America, Utah and Salt Lake City, we are gathered once again in your great country. Your nation is overcoming a horrific tragedy, a tragedy that has affected the whole world. ... We stand unified with you in the promotion of our common ideals and hopes for world peace ...

Rogge could hardly avoid mentioning the tragedy, and in these few words elided the universal Olympic message with the particular political philosophy of the world's foremost superpower. The US president, George W. Bush, then declared the Games open and Redcap reappeared in front of the Olympic flag, which was carried by eight bearers. Five of these represented the world's five continents, the others the three thematic pillars of the Olympic movement, sport, culture, and the environment. Barry Davies wondered aloud: "Surely it has never been previously carried by such a distinguished group of men, and one woman." The bearers were: for the Americas, spaceman John Glen; for Africa, religious leader and rights campaigner Desmond Tutu; for Europe, Polish politician Lach Walensa; for Asia, a Japanese 1998 Olympic medalist; for Oceania, Aboriginal gold-medal winner and opening ceremony flame-lighter Cathy Freeman; for sport, French skiing legend Jean-Claude Killy; for environment, Jean-Michel Cousteau, son of naturalist and environmentalist Jacques; and for culture, highly appropriate in the cultural specificity of the moment and the geographic setting, movie mogul Steven Spielberg. Rock star Sting then sang "let's not forget how fragile we are," and the ceremony moved to the climax of the lighting of the flame.

This was accomplished by the members of the US ice-hockey team that had defeated the Soviet 
Union at the 1980 Lake Placid Games. Igniting the flame for international peace, and so against the terrorism of the previous autumn/fall, was the team that had challenged the dominance of the Soviet/global threat (to the US) of the time. The team's coach recalled coming out of the dressing room and encountering state troopers in tears (Wallechinsky, 1994, p. 36). Where Salt Lake City began its ceremony with a breach of Olympic protocol in its honoring of the dead of $9 / 11$, it ended with a politicocultural celebration of a sporting triumph against the world's previous global threat to US supremacy.

\section{Conclusion}

There is a significant historical connection between large-scale cultural events, such as technological or cultural exhibitions staged for international audiences, and forms of tourism-related consumerism. Roche (2000, pp. 67-71) has elaborated on this, and his analysis provides a useful context for any discussion of how Olympic events exhibit any legacy of such a connection. For Roche, there are four main aspects of what he calls "touristic consumerism's" connection with such events. First, just to get to the events people are in an obvious sense tourists. They had to use new transport systems, and were pioneers of package travel. Second, they "were exposed to a powerful new consumerist world-view, that is to the concept and potential pleasures of a life filled with an endless variety and supply of buyable commodities" (p. 69). Third, the touristic consumers at expos in the late 1800s and early 1900s were emergently, though authentically, international in taste. They consumed products that "came from all over the world" (p. 69), that were associated with things foreign and exotic. Fourth, people and publics in the host nation encountered "others" in new ways, amounting to a kind of "tourism-without-the travel" (p. 70). The modern Olympic Games, linked as early ones were to expos and international exhibitions, were part of this broader development of an internationally framed touristic consumerism, which, as Roche observes, permeated into "popular consciousness and attitudes" (p. 70).

Nagano and Salt Lake City show how such a form of touristic consumerism continues to be framed a century and more after these initial forms of international exhibition or event. People attending such events are certainly sports tourists (Standeven \& De Knop, 1999) in a straightforward definitional, descriptive sense. Second, those attending Olympic events are, beyond the protected space of the stadium or the performance site, subjected to an assault from those consumer industries signed up with the IOC and with local organizing committees - typically, service industries providing soft drinks, fast food, insurance, personal health-care products, photographic equipment, communications, and information-technology goods; on through to street vendors pestering punters to purchase commemorative pins and badges. Third, an intriguing model of world culture is on show at the modern Olympics. The "other" is often reframed and homogenized into a series of bland costumes in the parade of the athletes. Commentary on such parades is trapped in triteness, perpetuating long-entrenched stereotypes of the nationalized "other," trivializing difference and cultural specificity. Fourth, the Olympics offers a "tourism-without-travel," particularly for the parochial publics of a remote or little-known region of Japan, or for a provincial city at the heartlands of the conservative US. The Winter Olympics may be less internationally representative, on the basis of the participating nations, than the Summer Olympics. But, with the arrestingly colorful setting of snow, clear skies, mountains, and daredevil style in performance, they have secured an established slot in the calendar of international sports events, and continue to be sought by potential city hosts and supporting national governments, these bidders often claiming long-term touristic benefits.

This is the point at which to evaluate more realistically any projected connection between the Olympic event and its immediate, contemporaneous tourist impact, and any more sustained or deep-rooted tourist legacy. It is widely assumed that there are multiple benefits in staging such events. Frank King chaired the organizing committee of the 1998 Calgary winter games, and after the event could confirm this: "No matter what city wins an Olympic bid, the city will benefit from the influx of tourists, the construction of new facilities, the promotion of sport, and the enhancement of civic pride" (King, 1991, p. 318).

Yet such benefits will not accrue automatically, and some are more obviously accomplished than others. King goes on from this reiteration of the con- 
ventional to expand on the final of these four claimed benefits. There would be short-term benefits from the presence and expenditure of visitors during the Games, but few longer term tourism benefits. The Canadian city would - as in many post-Olympic venues (Bale, 1994, 2003, pp. 127-128)-experience tensions over the future use of facilities. It is the "enhancement of civic pride" that emerges in accounts such as King's as the main benefit-the least tangible or measurable, yet the most deeply felt, benefit. King cited a letter to him, in the concluding pages of his book, from an emotional 20year-old volunteer, Patricia:

I was a ceremonies host during the Olympics and I led in the athletes for the opening and closing ceremonies. Never in my life have I felt so proud and never again will I feel that ecstatic high of thousands of people yelling for my country as I brought them in. ... All the crazy stuff going on in the world is making our youth awfully short. ... Thank you for giving us back the ability to dream and to make our dreams possible. (King, 1991, pp. 326-327)

It is this rhetoric of dream, renewal, and restoration that characterizes both the documented local responses of those involved in the staging of the event and the recurrent semantics of opening ceremonies (Tomlinson, 1996). There might have been "some grumbling about the choice of competition sites and the condition of the venues" (Wallechinsky, 1994, p. Xv) at Calgary, but this could not dent the sense of local and civic pride. Not all host cities start from the same base or balance the projected benefits in the same way. Lillehammer prided itself on getting "back to basics" and reframing the event around a "compact games," antigigantism concept (Puijk, 1997, p. 275). Puijk (2000) also reminds us that among the multiple meanings that the Olympic event generates in the interpretations of the global audience, tourist destination is conspicuous by its absence. Even in the most convincing case made for tourism benefits, it is important not to mistake longer term planning for short-term direct effect. Kennett and de Moragas caution against such analytical indiscretions: "The growth of tourism in Barcelona can be highlighted as one of the most important legacies of the investment in urban infrastructure and the publicity the Olympic Games provided. However, this legacy was not inevitable; it was achieved through the continued investment in Barcelona's tourist destination product and its promotion" (in press). In 1990 Barcelona attracted 1.7 million tourists. By 2002, 3.6 million tourists were visiting the city. The motivation cited for the visit also shifted from business, which drew 69\% of 1990's visitors, to leisure (49\% against $47 \%$ visiting for business) in 2002. Barcelona's tourist market was also internationalized in this period: under half of tourists came from abroad in 1990, over two thirds by 2002 . It would be absurd to ignore the legacy and impact of the Olympics in this success story. But such impacts continue to be hard to measure, and impossible to compare.

The Barcelona case remains a special one, fueled after the Games by an ambitious and politically driven regional politics. But some events may even have worked against the expansion of tourist markets. During the Los Angeles 1984 Games, "the Los Angeles and Southern California regional economy experienced some displacement of normal tourism and regional resident expenditure patterns" (Economics Research Associates [ERA], 1986, p. 7), after reaching a record high in 1982. Why? A highly valued US dollar drew US travelers abroad; anticipated congestion and pumped-up prices "had negative effects on potential summer tourists and visitors" (p. 7); a 6-year lead-in enabled locals to plan to get out of town, and businesses to postpone trips; regional residents who stayed in town for the event spent disposable income on the Olympics, rather than and not in addition to other recreational activities. It was estimated (ERA, 1986, p. 9) that this displacement value may have reached $\$ 331.0$ million.

On October 21 2003, the search engine Google offered 1,040,000 results when "Salt Lake City Tourism" was entered. The words "Nagano Tourism" generated a mere 5670 results. Information from Nagano Prefecture Tourism made reference to its 1998 moment on the world stage:

during this time Nagano was able to impress the people of the world. The eyes of not only Japan but those of the whole world focused on our Prefecture as a winter sports region operating in harmony with nature and modern transportation developments.

But there is an air of realism in this statement. Whatever the messages and meanings of the open- 
ing ceremonies of Nagano and Salt Lake City, it was never likely that these events alone, and the way in which they were represented in the world media, would have a transformative effect upon their place in the international tourist market. Close analysis of the opening ceremonies of these two events confirms that, whatever the aspirations in and projections of the bidding process, the pictures of the event are most eagerly waited and best remembered by the hosts themselves, and their own regional and national constituencies.

\section{References}

Arup (in association with: Insignia Richard Ellis). (2002, May 21). London Olympics 2012, costs and benefits: Summary.

Bale, J. (1994). Landscapes of modern sport. London: Leicester University Press.

Bale, J. (2003). Sports geography (2nd ed.). London: Routledge.

de Moragas, M., \& Botella, M. (Eds.). (1995) The keys to success: The social, sporting, economic and communications impact of Barcelona '92. Barcelona: Centre for Olympic and Sport Studies/ Autonomous University of Barcelona.

Economics Research Associates. (1986). Community economic impact of the 1984 Olympic Games in Los Angeles-Executive summary (prepared for the Los Angeles Olympic Organizing Committee October 1984, updated June 1986 for the Los Angeles Area Chamber of Commerce). Los Angeles: Author.
Jennings, A., \& Sambrook, C. (2000). The great Olympic swindle: When the world wanted its Games back. London: Simon \& Schuster.

Kennett, C., \& de Moragas, M. (in press) The Barcelona '92 Olympic Games: Evaluating the legacies. In A. Tomlinson \& C. Young (Eds.), National identity and international sporting events: Culture, politics and spectacle in the Olympic Games and the football World Cup. Albany, NY: State University of New York Press.

King, F. J. (1991). It's how you play the game-the inside story of the Calgary Olympics. Calgary: Script, the writers' group inc.

Puijk, R. (Ed.). (1997). Global spotlights on Lilllehammerhow the world viewed Norway during the 19994 Winter Olympics. Luton: University of Luton Press/John Libbey Media.

Puijk, R. (2000). A global media event? Coverage of the 1994 Lillehammer Olympic Games. International Review for the Sociology of Sport, 35(3), 309-330.

Roche, M. (2000). Mega-events and modernity: Olympics and expos in the growth of global culture. London: Routledge.

Simson, V., \& Jennings, A. (1992). The lords of the rings: Power, money and drugs at the Olympics. London: Simon $\&$ Schuster.

Standeven, J., \& De Knop, P. (1999). Sport tourism. Champaign: IL: Human Kinetics.

Tomlinson, A. (1996). Olympic spectacle: Opening ceremonies and some paradoxes of globalization. Media, Culture \& Society, 18(4), 583-602.

Wallechinsky, D. (1994). The complete book of the Winter Olympics (1994 ed.). London: Aurum Press Ltd. 